\title{
RESPONS MAHASISWA TERHADAP PENGGUNAAN MODUL "SEDEKAH, HIBAH, DAN HADIAH" PADA MATA KULIAH PENDIDIKAN AGAMA ISLAM DI AKADEMI FARMASI AL-FATAH BENGKULU
}

Nanik

*Dosen Pendidikan Agama Islam Akademi Farmasi Al-Fatah Bengkulu

Contact Person: Telp. 0852-6834-1566, e-mail : nanik.lestari58@yahoo.com

\begin{abstract}
The formulation of the problem in this study is how students respond to learning Islamic Education (PAI) courses using the "Alms, Grants and Gifts" module at the Bengkulu Al-Fatah Pharmacy Academy. This research is included in quantitative descriptive research. The population in this study were all third semester students at the Bengkulu Al-Fatah Pharmacy Academy, while the research sample used was third semester B1 students at the Al-Fatah Pharmacy Academy Bengkulu Academic Year 2016-2017. The instruments used in this study were the student response questionnaire and the module "Alms, Grants and Gifts". The technique of collecting data using questionnaires and test sheets. Based on the research that has been done, the results show that : The average percentage score of all students is $82.86764706 \%$ and is classified as very high criteria. It can be concluded that the 3rd grade B1 Semester 3-2017 Academic Year at the Al-Fatah Pharmacy Academy gave a positive response to the learning of Islamic Education courses using the "Alms, Grants, and Gifts" module.

Keywords: response, student, module.
\end{abstract}

\begin{abstract}
Abstrak: Rumusan masalah dalam penelitian ini adalah bagaimana respon mahasiswa terhadappembelajan mata kuliah Pendidikan Agama Islam (PAI) menggunakan modul "Sedekah, Hibah dan Hadiah" di Akademi Farmasi Al-Fatah Bengkulu. Penelitian ini termasuk dalam penelitian deskriptif kuantitatif. Populasi dalam penelitian ini adalah seluruh mahasiswa semester III di Akademi Farmasi Al-Fatah Bengkulu, sedangkan sampel penelitian yang digunakan adalah mahasiswa semester III B1 di Akademi Farmasi Al-Fatah Bengkulu Tahun Ajaran 2016-2017. Instrumen yang digunakan dalam penelitian ini adalah lembar angket respons mahasiswa dan modul "Sedekah, Hibah dan Hadiah". Teknik pengumpulan data menggunakan lembar kuesioner dan lembar tes. Berdasarkan penelitian yang telah dilakukan didapatkan hasil bahwa: Persentase rata-rata skor semua mahasiswa yaitu sebesar $82,86764706 \%$ dan tergolong ke dalam kriteria sangat tinggi. Dapat disimpulkan bahwa mahasiswa Semester 3 kelas B1 Tahun Ajaran 2016-2017 di Akademi Farmasi Al-Fatah memberikan respons yang positif terhadap pembelajaran mata kuliah Pendidikan Agama Islam menggunakan modul "Sedekah, Hibah, dan Hadiah".
\end{abstract}

Kata Kunci: respons, mahasiswa, modul.

\section{Pendahuluan}

Pendidikan merupakan hal yang sangat penting untuk diperhatikan saat ini. Pendidikan bukanlah sekedar wacana untuk membentuk anak-anak muda dapat menjadi generasi yang kompeten, melainkan pendidikan menekankan bagaimana proses tersebut dapat diterapkan. Pendidikan merupakan suatu proses interaksi yang mendorong terjadinya peristiwa belajar. Karena dengan adanya belajar, terjadilah perkembangan jasmani dan mental siswa. ${ }^{1}$

'Dimyati dan Mudjiono.Belajar Dan Pembelajaran,(Jakarta: Rineka Cipta, 2009), h. 5.

26

NUANSA Vol. XI, No. 1, Juni 2018
Seiring dengan perkembangan ilmu pengetahuan dan teknologi, peserta didik (dalam hal ini mahasiswa) bukan lagi berkedudukan sebagai penerima ilmu pengetahuan dan pendidik (dalam hal ini adalah guru dan dosen) merupakan pemberi pengetahuan atau sering disebut sebagai pembelajaran dengan teacher oriented. Peserta didik dibiasakan untuk mengkonstruksi pengetahuan baru dengan mengintegrasikan dengan pengetahuan sebelumnya, sedangkan guru dan dosen sebagai pendidik bertindak sebagai fasilisator. Pembelajaran tidak lagi berpusat pada guru dan dosen (teacher oriented) namun berpusat pada siswa (student oriented). Guru ataupun dosen dalam proses ini 
berfungsi sebagai mediator dan fasilisator.

Dalam melaksanakan pembelajaran yang berpusat pada peserta didik, pendidik berupaya untuk menciptakan berbagai cara yang memungkinkan peserta didik menjadi aktif dalam mencari pengetahuannya sendiri. Salah satu cara yaitu dengan menyusun sebuah bahan ajar berupa modul. Menurut Kamus Besar Bahasa Indonesia, modul diartikan sebagai kegiatan program belajar mengajar yang dapat dipelajari oleh peserta didik dengan bantuan minimal dari guru atau pembimbing yang meliputi perencanaan tujuan yang jelas, penyediaan materi pelajaran, alat yang dibutuhkan, serta pengukuran keberhasilan peserta didik dalam menyelesaikan pelajaran. Modul merupakan salah satu bentuk bahan ajar yang dikemas secara utuh dan sistematis, didalamnya memuat seperangkat pengalaman belajar yang terencana dan didesain untuk membantu peserta didik menguasai tujuan belajar yang spesifik. Sementara itu, modul juga diartikan sebagai sebuah buku yang ditulis dengan tujuan agar peserta didik dapat belajar secara mandiri tanpa atau dengan bimbingan guru. Dari beberapa pengertian tersebut, dapat disimpulkan bahwa modul adalah suatu media pembelajaran yang berupa sebuah bahan ajar dan digunakan dalam membantu prosees belajar mengajar, serta disusun secara sistematis dengan bahasa yang mudah dipahami oleh peserta didik sesuai dengan tingkat pengetahuan agar peserta didik mampu belajar mandiri dengan atau tanpa bimbingan dari guru atau pembimbing.

Modul minimal memuat tujuan pembelajaran, materi/substansi belajar, dan evaluasi. Modul berfungsi sebagai sarana belajar yang bersifat mandiri, sehingga peserta didik dapat belajar sesuai dengan kecepatan masing-masing. Untuk menghasilkan modul yang mampu meningkatkan motivasi belajar, pengembangan modul harus memperhatikan karakteristik.

Karakteristik yang diperlukan suatu modul antara lain sebagai berikut :2

a. Self instructional, Siswa mampu membelajarkan diri sendiri, tidak tergantung pada pihak lain.

b. Self contained, Seluruh materi pembelajaran

2Anwar,Pengembangan Bahan Ajar,(Bandung: Direktori Upi, 2010), dari satu unit kompetensi yang dipelajari terdapat didalam satu modul utuh.

c. Stand alone, Modul yang dikembangkan tidak tergantung pada media lain atau tidak harus digunakan bersama-sama dengan media lain.

d. Adaptif, Modul hendaknya memiliki daya adaptif yang tinggi terhadap perkembangan ilmu dan teknologi.

e. User friendly, Modul hendaknya juga memenuhi kaidah akrab bersahabat/akrab dengan pemakainya.

f. Konsistensi, Konsisten dalam penggunaan font, spasi, dan tata letak.

Di dalam suatu proses pembelajaran, penggu-

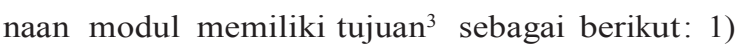
Memperjelas dan mempermudah penyajian pesan agar tidak terlalu bersifat verbal; 2) Mengatasi keterbatasan waktu, ruang, dan daya indra; 3) Dapat digunakan secara tepat dan bervariasi seperti meningkatkan motivasi dan gairah belajar bagi peserta didik; 4) Mengembangkan kemampuan peserta didik dalam berinteraksi langsung dengan lingkungan dan sumber belajar lainnya; 5) Memungkinkan peserta didik belajar mandiri sesuai kemampuan dan minatnya.

Modul sebagai satu unit program belajar-mengajar terkecil yang secara rinci terdapat: ${ }^{4}$

a. Tujuan instruksional yang akan dicapai

b. Topik yang akan dijadikan dasar proses belajarmengajar

c. Pokok-pokok materi yang dipelajari

d. Kedudukan dan fungsi modul dalam kesatuan program yang lebih luas

e. Peranan guru dalam proses belajar-mengajar

f. Alat-alat dan sumber yang akan dipergunakan

g. Kegiatan-kegiatan belajar yang harus dilakukan dan dihayati murid secara berurutan

h. Lembaran kerja yang harus diisi oleh siswa

i. Program evaluasi yang akan dilaksanakan

Belajar menggunakan modul sangat banyak manfaatnya, siswa dapat bertanggung jawab ter-

${ }^{3}$ Direktorat Jenderal Manajemen Pendidikan Dasar dan Menengah, Teknik Penyusunan Modul,(Jakarta: Departemen Pendidikan Nasional, 2008), h.........

Sudjana dan Ahmad,Media Pengajaran,(Bandung: Sinar Baru Algesindo, 2007), h. 1-7. 
hadap kegiatan belajarnya sendiri, pembelajaran dengan modul sangat menghargai perbedaan individu, sehingga siswa dapat belajar sesuai dengan tingkat kemampuannya maka pembelajaran semakin efektif dan efisien.

Keuntungan yang diperoleh jika belajar menggunakan modul ${ }^{5}$ antara lain :1) Motivasi siswa dipertinggi karena setiap kali siswa mengerjakan tugas pelajaran dibatasi dengan jelas dan yang sesuai dengan kemampuannya; 2) Sesudah pelajaran selesai guru dan siswa mengetahui benar siswa yang berhasil dengan baik dan mana yang kurang berhasil; 3) Siswa mencapai hasil yang sesuai dengan kemampuannya; 4) Beban belajar terbagi lebih merata sepanjang semester; dan 5) Pendidikan lebih berdaya guna.

Sementara itu, penggunaan modul juga memiliki kelemahan ${ }^{6}$, antara lain: 1) Biaya pengembangan bahan tinggi dan waktu yang dibutuhkan lama; 2) Menentukan disiplin belajar yang tinggi yang mungkin kurang dimiliki oleh siswa pada umumnya dan siswa yang belum matang pada khususnya; dan 3) Membutuhkan ketekunan yang lebih tinggi dari fasilitator untuk terus menerus mamantau proses belajar siswa, memberi motivasi dan konsultasi secara individu setiap waktu siswa membutuhkan.

Pembelajaran menggunakan modul diharapkan dapat efektif mengubah konsepsi peserta didik menuju konsep ilmiah, sehingga hasil belajar dapat ditingkatkan seoptimal mungkin baik dari segi kualitas maupun kuantitasnya. Kesuksesan belajar menggunakan modul tergantung pada kriteria peserta didik yang didukung oleh pembelajaran tutorial. Kriteria ini meliputi ketekunan, waktu untuk belajar, kadar pembelajaran, mutu kegiatan pembelajaran dan kemampuan memahami petunjuk di dalam modul.

Penelitian ini bertujuan untuk mengetahui respons mahasiswa semester III kelas B1 Tahun Ajaran 2016-2017 di Akademi Farmasi Al-Fattah Bengkuluterhadap pembelajaran menggunakan modul "Sedekah, Hibah dan Hadiah".

\section{Metode Penelitian}

Penelitian ini menggunakan metode deskriptif. Metode deskriptif akan menggambarkan keadaan variabel yang diteliti ${ }^{7}$, dan bertujuan untuk memberikan gambaran atau deskripsi menggunakan ukuran, jumlah atau frekuensi yang teratur, ring- kas, dan jelas mengenai suatu gejala, peristiwa atau keadaan, sehingga dapat ditarik pengertian atau makna-makna tertentu. ${ }^{8}$ Dalam penelitian ini, metode deskriptif digunakan untuk memperoleh deskripsi mengenai respons mahasiswasemester III kelas B1 Tahun Ajaran 2016-2017 di Akademi Farmasi Al-Fatah Bengkulu.

Dalam penelitian ini dilakukan prosedur antara lain: menyusun modul pembelajaran yang berjudul "Sedekah, Hibah dan Hadiah", menentukan populasi dan sampel penelitian, menyusun instrumen penelitian yang berupa kuesioner atau angket, mengambil data di lapangan, serta mengolah dan menganalisis data.

Teknik pengumpulan data dalam penelitian ini menggunakan kuesioner.Sedangkan intrumen penelitian yang digunakan adalah lembar angket respons. Pada lembar angket respons ini terdapat 10 butir pernyataan dengan kriteria respons sangat tidak setuju, tidak setuju, setuju, dan sangat setuju.

Langkah-langkah yang dilakukan untuk menganalisis angket yaitu: 1) Memeriksa setiap jawaban angket yang dipilih siswa, 2) Merekapitulasi jawaban angket mengenai respons mahasiswa terhadap modul pembelajaran "Sedekah, Hibah dan Hadiah". Dalam penelitian ini perolehan skor untuk masingmasing jawaban adalah sebagai berikut: respons sangat tidak setuju memiliki skor 1, respons tidak setuju memiliki skor 2, respons setuju memiliki skor 3, dan respons sangat setuju memiliki skor 4, 3) Menghitung persentase skor per item, 4) Menghitung persentase rata-rata skor angket, 5) Melakukan interpretasi rata-rata skor angket dengan menggunakan skala Likert yang dimodifikasi dari Riduwan (2008) yaitu angka $0 \%-20 \%$ = sangat rendah, $21 \%$ $40 \%=$ rendah, $41 \%-60 \%$ = cukup, $61 \%-80 \%=$ tinggi, dan $81 \%-100 \%=$ sangat tinggi, dan 6) Mendeskripsikan respons mahasiswa terhadap penerapan modul pembelajaran "Sedekah, Hibah, dan Hadiah" pada mata kuliah Pendidikan Agama Islam (PAI) berdasarkan hasil angket.

\section{Pembahasan}

Dalam KBBI ${ }^{9}$ (Kamus Besar Bahasa Indonesia), respons diartikan sebagai tanggapan, reaksi, dan jawaban.Seseorang dikatakan memberikan respons yang positif apabila bagi seseorang tersebut sesuatu yang diberikan respon itu menarik.Respons siswa terhadappenggunaanmediapembelajaran10(dalam 
penelitian ini adalah modul) oleh guru dapat dilihat dari ekspresi, pendapat langsung perihal ketertarikan terhadap media tersebut, mudah atau sulitnya memahami pesan pembelajaran dalam media tersebut, serta bagaimana motivasi siswa setelah menyimak pembelajaran dengan menggunakan media.

Dalam penelitian ini, responsmahasiswa terhadap pembelajaran mata kuliah Pendidikan Agama Islam menggunakan modul "Sedekah, Hibah dan Hadiah" dilihat melalui angket/kuesioner. Pada saat pembelajaran, dosen memberikan seperangkat modul kepada mahasiswa.Setelah pembelajaran menggunakan media pembelajaran berupa modul "Sedekah, Hibah dan Hadiah", maka dosen menyebarkan angket untuk diisi oleh mahasiswa. Angket tersebut diberikan kepada mahasiswa di akhir kegiatan proses pembelajaran. Mahasiswa diminta menjawab dengan jujur terhadap pernyataan yang berkaitan dengan pendapat mahasiswa mengenai pembelajaran mata kuliah Pendidikan Agama Islam menggunakan modul "Sedekah, Hibah dan Hadiah" oleh Dosen mata kuliah PAI. Adapun skor dari jawaban angket tersebut yaitu sebagai berikut:

Tabel 1. Skor jawaban mahasiswa dan respons mahasiswa per kriteria butir angket

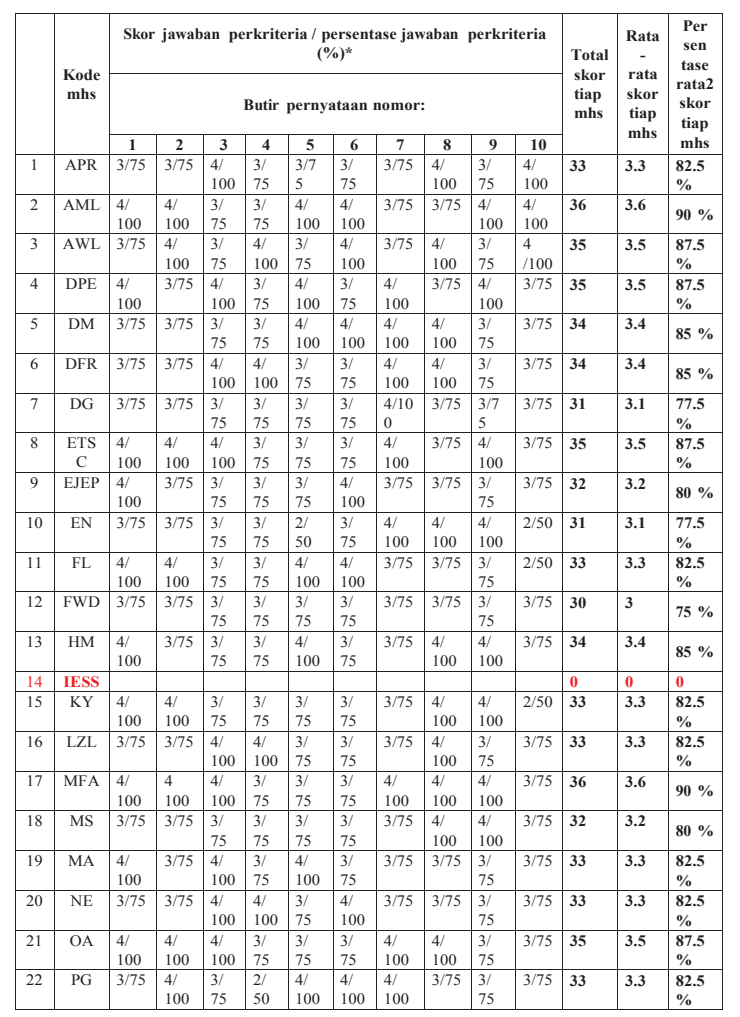

\begin{tabular}{|c|c|c|c|c|c|c|c|c|c|c|c|c|c|c|}
\hline 23 & $\mathrm{RM}$ & 3/75 & 3/75 & $\begin{array}{l}3 / \\
75\end{array}$ & \begin{tabular}{|l|}
$4 /$ \\
100 \\
\end{tabular} & \begin{tabular}{|l|}
$3 /$ \\
75 \\
\end{tabular} & \begin{tabular}{|l|}
$3 /$ \\
75 \\
\end{tabular} & \begin{tabular}{|l|l|}
$3 / 75$ \\
\end{tabular} & $3 / 75$ & $\begin{array}{l}2 / \\
50 \\
\end{array}$ & $3 / 75$ & \begin{tabular}{|l|}
30 \\
\end{tabular} & 3 & $75 \%$ \\
\hline 24 & $\overline{R Y}$ & \begin{tabular}{|l|}
$4 /$ \\
100
\end{tabular} & \begin{tabular}{|l|}
$4 /$ \\
100
\end{tabular} & $\begin{array}{l}4 / \\
100\end{array}$ & \begin{tabular}{|l|}
$4 /$ \\
100
\end{tabular} & \begin{tabular}{|l|}
$3 /$ \\
75
\end{tabular} & $\begin{array}{l}3 / \\
75\end{array}$ & $3 / 75$ & $3 / 75$ & \begin{tabular}{|l}
$3 /$ \\
75
\end{tabular} & \begin{tabular}{|l|}
$3 / 75$ \\
\end{tabular} & 34 & 3.4 & $85 \%$ \\
\hline 25 & RDP & $3 / 75$ & \begin{tabular}{|l|}
$4 /$ \\
100
\end{tabular} & $\begin{array}{l}4 / \\
100\end{array}$ & \begin{tabular}{|l|}
$4 /$ \\
100
\end{tabular} & $\begin{array}{l}3 / \\
75\end{array}$ & $\begin{array}{l}3 / \\
75\end{array}$ & 3/75 & $3 / 75$ & \begin{tabular}{|l|}
$4 /$ \\
100
\end{tabular} & $3 / 75$ & 34 & 3.4 & $85 \%$ \\
\hline 26 & RT & $3 / 75$ & $3 / 75$ & $\begin{array}{l}3 / \\
75\end{array}$ & $\begin{array}{l}3 / \\
75\end{array}$ & $\begin{array}{l}3 / \\
75 \\
\end{array}$ & $\begin{array}{l}3 / \\
75 \\
\end{array}$ & $\begin{array}{l}4 / \\
100\end{array}$ & $\begin{array}{l}4 / \\
100\end{array}$ & \begin{tabular}{|l|}
$4 / 1$ \\
100 \\
\end{tabular} & \begin{tabular}{|l|}
$2 / 50$ \\
\end{tabular} & 32 & 3.2 & $80 \%$ \\
\hline 27 & SAH & $3 / 75$ & $3 / 75$ & 75 & \begin{tabular}{|l}
$3 /$ \\
75
\end{tabular} & \begin{tabular}{|l|l|}
$4 /$ \\
100
\end{tabular} & \begin{tabular}{|l|l|}
$4 /$ \\
100
\end{tabular} & \begin{tabular}{|l|l|}
$4 /$ \\
100
\end{tabular} & $3 / 75$ & $\begin{array}{l}3 / \\
75\end{array}$ & \begin{tabular}{|l|}
$3 / 75$ \\
\end{tabular} & 33 & 3.3 & \begin{tabular}{|l|l|}
82.5 \\
$\%$
\end{tabular} \\
\hline 28 & $\overline{\mathrm{SG}}$ & \begin{tabular}{|l|l|}
$4 / 00$ \\
100
\end{tabular} & $\begin{array}{l}1100 \\
4\end{array}$ & 75 & $\begin{array}{l}3 / \\
75\end{array}$ & \begin{tabular}{|l|l|}
$4 /$ \\
100
\end{tabular} & $\begin{array}{l}3 / \\
75\end{array}$ & \begin{tabular}{|l|}
$4 /$ \\
100
\end{tabular} & $\begin{array}{l}3 / 75 \\
\end{array}$ & \begin{tabular}{|l|l|}
$4 /$ \\
100
\end{tabular} & $3 / 75$ & 35 & 3.5 & $\begin{array}{l}87.5 \\
\%\end{array}$ \\
\hline 29 & SR & $3 / 75$ & $3 / 75$ & $7 /$ & \begin{tabular}{|l|}
$4 /$ \\
100
\end{tabular} & \begin{tabular}{|l|}
$4 /$ \\
100 \\
\end{tabular} & \begin{tabular}{|l|}
$4 /$ \\
100
\end{tabular} & 3/75 & $3 / 75$ & \begin{tabular}{|l|}
$4 /$ \\
100
\end{tabular} & \begin{tabular}{|l|}
$2 / 50$ \\
\end{tabular} & 33 & 3.3 & \begin{tabular}{|l|}
82.5 \\
$\%$
\end{tabular} \\
\hline 30 & TM & \begin{tabular}{|l|}
$3 / 75$ \\
\end{tabular} & \begin{tabular}{|l|}
$3 / 75$ \\
\end{tabular} & $\begin{array}{l}3 / \\
75 \\
\end{array}$ & $\begin{array}{l}3 / \\
75\end{array}$ & \begin{tabular}{|l|}
$4 /$ \\
100 \\
\end{tabular} & \begin{tabular}{|l|}
$4 /$ \\
100 \\
\end{tabular} & \begin{tabular}{|l|}
$3 / 75$ \\
\end{tabular} & $3 / 75$ & $\begin{array}{l}/ 3 \\
75 \\
\end{array}$ & \begin{tabular}{|l|}
$3 / 75$ \\
\end{tabular} & 32 & 3.2 & $80 \%$ \\
\hline 31 & TS & \begin{tabular}{|l|}
$3 / 75$ \\
\end{tabular} & \begin{tabular}{|l|}
$4 /$ \\
100 \\
\end{tabular} & $\begin{array}{l}4 / \\
100\end{array}$ & \begin{tabular}{|l|}
$3 / 7$ \\
5 \\
\end{tabular} & $\begin{array}{l}3 / \\
75\end{array}$ & \begin{tabular}{|l|}
$4 /$ \\
100 \\
\end{tabular} & $3 / 75$ & $3 / 75$ & $\begin{array}{l}3 / \\
75\end{array}$ & \begin{tabular}{|l|}
$3 / 75$ \\
\end{tabular} & 33 & 3.3 & \begin{tabular}{|l}
82.5 \\
$\%$
\end{tabular} \\
\hline 32 & YAL & $3 / 75$ & $3 / 75$ & 75 & \begin{tabular}{|l|}
$4 /$ \\
100 \\
\end{tabular} & \begin{tabular}{|l|l|}
$4 /$ \\
100
\end{tabular} & $\begin{array}{l}3 / \\
75\end{array}$ & $3 / 75$ & \begin{tabular}{|l|l|}
$4 /$ \\
100
\end{tabular} & $\begin{array}{l}3 / \\
75\end{array}$ & $2 / 50$ & 32 & 3.2 & $80 \%$ \\
\hline 33 & BRS & $3 / 75$ & \begin{tabular}{|l|}
$4 /$ \\
100
\end{tabular} & \begin{tabular}{|l|}
$2 /$ \\
50
\end{tabular} & \begin{tabular}{|l|}
$4 /$ \\
100
\end{tabular} & $\begin{array}{l}3 / \\
75\end{array}$ & $\begin{array}{l}3 / \\
75\end{array}$ & $3 / 75$ & \begin{tabular}{|l|}
$3 / 75$ \\
\end{tabular} & $\begin{array}{l}3 / \\
75\end{array}$ & \begin{tabular}{|l|l|}
$4 /$ \\
100
\end{tabular} & 32 & 3.2 & $80 \%$ \\
\hline 34 & F & \begin{tabular}{|l|}
$3 / 75$ \\
\end{tabular} & $3 / 75$ & $\begin{array}{l}3 / \\
75\end{array}$ & \begin{tabular}{|l|}
$4 /$ \\
100
\end{tabular} & \begin{tabular}{|l|l|}
$4 /$ \\
100
\end{tabular} & $\begin{array}{l}3 / \\
75\end{array}$ & $3 / 75$ & \begin{tabular}{|l|}
$4 /$ \\
100
\end{tabular} & $\begin{array}{l}/ \\
75\end{array}$ & \begin{tabular}{|l|l|}
$4 /$ \\
100
\end{tabular} & 34 & 3.4 & $85 \%$ \\
\hline 35 & M & \begin{tabular}{|l|}
$3 / 75$ \\
\end{tabular} & $3 / 75$ & \begin{tabular}{|l|}
$4 /$ \\
100 \\
\end{tabular} & \begin{tabular}{|l|}
$4 /$ \\
100 \\
\end{tabular} & \begin{tabular}{|l|}
$3 /$ \\
75 \\
\end{tabular} & \begin{tabular}{|l|}
$2 /$ \\
50 \\
\end{tabular} & $\begin{array}{l}4 / \\
100 \\
\end{array}$ & $3 / 75$ & $\begin{array}{l}/ \\
75\end{array}$ & \begin{tabular}{|l|}
$3 / 75$ \\
\end{tabular} & 32 & 3.2 & $80 \%$ \\
\hline & $\begin{array}{l}\text { al skor } \\
\text { aban } \\
\text { er } \\
\text { iteria }\end{array}$ & 114 & 115 & 114 & 113 & \begin{tabular}{|l|l|}
114 &
\end{tabular} & 112 & 115 & 116 & 113 & 101 & 1127 & $\begin{array}{c}112, \\
7\end{array}$ & $\underset{5}{2817}$ \\
\hline & $\begin{array}{l}\text { a-rata } \\
\text { al skor } \\
\text { aban } \\
\text { ear } \\
\text { teria }\end{array}$ & \begin{tabular}{|l|}
3,35 \\
294 \\
1117 \\
6
\end{tabular} & \begin{tabular}{l|}
3,38 \\
2235 \\
294 \\
1
\end{tabular} & \begin{tabular}{l|}
3,3 \\
559 \\
411 \\
76
\end{tabular} & \begin{tabular}{l|}
3,3 \\
235 \\
294 \\
12
\end{tabular} & \begin{tabular}{|l|}
3,35 \\
294 \\
117 \\
6
\end{tabular} & \begin{tabular}{|l|}
3,2 \\
941 \\
176 \\
47
\end{tabular} & $\begin{array}{l}3,38 \\
235 \\
294 \\
1\end{array}$ & \begin{tabular}{|l|}
3,41 \\
176 \\
470 \\
6
\end{tabular} & \begin{tabular}{|l|}
3,32 \\
352 \\
941 \\
2
\end{tabular} & \begin{tabular}{|l|}
2,97 \\
058 \\
823 \\
5
\end{tabular} & \begin{tabular}{|l|}
33.14 \\
7058 \\
82
\end{tabular} & \begin{tabular}{|l|}
3.31 \\
4705 \\
882
\end{tabular} & \begin{tabular}{|l|}
82,86 \\
7647 \\
06
\end{tabular} \\
\hline & $\begin{array}{l}\text { entase } \\
\text { aban } \\
\text { aha } \\
\text { va per } \\
\text { teria }\end{array}$ & \begin{tabular}{|l|}
83,8 \\
235 \\
294 \\
$1 \%$ \\
\end{tabular} & \begin{tabular}{|l|}
$\mathbf{8 4 , 5}$ \\
$\mathbf{5 8 8}$ \\
$\mathbf{2 3 5}$ \\
$3 \%$ \\
$\mathbf{3}$
\end{tabular} & \begin{tabular}{|l|}
83, \\
823 \\
529 \\
41 \\
$\%$ \\
\end{tabular} & \begin{tabular}{|l|}
$\mathbf{8 3}$, \\
$\mathbf{0 8 8}$ \\
$\mathbf{2 3 5}$ \\
$\mathbf{2 9}$ \\
$\%$ \\
\end{tabular} & \begin{tabular}{|l|}
83,8 \\
235 \\
294 \\
$1 \%$
\end{tabular} & \begin{tabular}{|l|}
82, \\
352 \\
941 \\
18 \\
$\%$ \\
\end{tabular} & \begin{tabular}{|l|}
$\mathbf{8 4 , 5}$ \\
$\mathbf{5 8 8}$ \\
$\mathbf{2 3 5}$ \\
$\mathbf{3} \%$
\end{tabular} & \begin{tabular}{|l|}
85,2 \\
941 \\
176 \\
$5 \%$
\end{tabular} & \begin{tabular}{|l|}
83,0 \\
882 \\
352 \\
$9 \%$
\end{tabular} & \begin{tabular}{|l|}
74,2 \\
647 \\
058 \\
$8 \%$
\end{tabular} & \begin{tabular}{|l|}
828,6 \\
7667 \\
06
\end{tabular} & \begin{tabular}{|l|}
82,8 \\
6764 \\
706
\end{tabular} & \begin{tabular}{|l|}
2071 \\
6911 \\
76
\end{tabular} \\
\hline
\end{tabular}

*Keterangan :

1. Saya menyukai pembelajaran PAI (Pendidikan Agama Islam) menggunakan modul daripada harus mencari bahan/materi sendiri

2. Pembelajaran PAI (Pendidikan Agama Islam) menggunakan modul lebih mudah dimengerti daripada tidak menggunakan modul

3. Pembelajaran PAI (Pendidikan Agama Islam) menggunakan modul memunculkan motivasi saya untuk belajar

4. Dengan adanya modul'Sedekah, Hibah, dan Hadiah,' penjelasan dosen lebih mudah dimengerti dan dipahami.

5. Saya tidak merasa kesulitan dalam memahami isi modul Sedekah, Hibah, dan Hadiah

6. Struktur kalimat yang digunakan dalam modul ini jelas dan sederhana

7. Bahasa yang digunakan dalam modul ini mudah dipahami dan komunikatif

8. Penyajian modul disesuaikan dengan daftar pustaka

9. Dengan adanya modul Sedekah, Hibah, dan Hadiah, saya dapat belajar secara mandiri

10. Modul dilengkapi dengan gambar, tabel dan grafik yang menarik

Hasil yang diperoleh melalui angket menunjukkan bahwa mahasiswa kelas B1 memberikan 
respons postif terhadap pembelaran mata kuliah Pendidikan agama Islam menggunakan modul "Sedekah, Hibah, dan Hadiah". Hal ini dapat terlihat pada tabel 1 mengenai skor jawaban mahasiswa dan respons mahasiswa per kriteria butir angket.

Pada butir pernyataan nomor 1 yaitu: Saya menyukai pembelajaran PAI (Pendidikan Agama Islam) menggunakan modul daripada harus mencari bahan/materi sendiri, dari 34 mahasiswa yang mengisi lembar angket, didapatkan total skor jawaban per kriteria sebesar 114, dengan rata-rata total skor jawaban per kriteria sebesar 3,352941176, atau dibulatkan menjadi 3,35. Angka 3,35 ini menandakan bahwa dari 34 mahasiswa tersebut memberikan skor rata-rata dengan kriteria setuju, atau secara keseluruhan, mahasiswa merespons bahwa pada pembelajaran PAI (Pendidikan Agama Islam) menggunakan modul lebih disukai daripada harus mencari bahan/materi sendiri. Sedangkan pada perhitungan persentase jawaban mahasiswa per kriteria didapatkan sebesar 83,82352941 \% atau dibulatkan sebesar 83,82\%. Berdasarkan skala Likert, angka ini masuk ke dalam kategori respon sangat tinggi.Hal ini menunjukkan bahwa secara menyeluruh, mahasiswa kelas B1 merespons dengan sangat baik butir pernyataan nomor 1 ini.

Pernyataan nomor 2 yaitu: Pembelajaran PAI (Pendidikan Agama Islam) menggunakan modul lebih mudah dimengerti daripada tidak menggunakan modul, dari 34 mahasiswa yang mengisi lembar angket, didapatkan total skor jawaban per kriteria sebesar 115, dengan rata-rata total skor jawaban per kriteria sebesar 3,382352941, atau dibulatkan menjadi 3,38. Angka 3,38 ini menandakan bahwa dari 34 mahasiswa tersebut memberikan skor rata-rata dengan kriteria setuju, atau secara keseluruhan, mahasiswa merespons bahwa penggunaan modul "Sedekah, Hibah, dan Hadiah" pada pembelajaran PAI (Pendidikan Agama Islam) lebih mudah dimengerti oleh mahasiswa kelas B1 tersebut. Sedangkan pada perhitungan persentase jawaban mahasiswa per kriteria didapatkan sebesar 83,82352941 $\%$ atau dibulatkan sebesar 83,82 \%. Berdasarkan skala Likert, angka ini masuk ke dalam kategori respons sangat tinggi.Hal ini menunjukkan bahwa mahasiswa kelas B1 secara umum merespons butir pernyataan nomor 2 dengan sangat baik.

Pada butir pernyataan nomor 3 yaitu: Pembelajaran PAI(Pendidikan Agama Islam) menggunakan modul memunculkan motivasi saya untuk belajar, dari 34 mahasiswa yang mengisi lembar angket, didapatkan total skor jawaban per kriteria sebesar 114, dengan rata-rata total skor jawaban per kriteria sebesar 3,352941176, atau dibulatkan menjadi 3,35. Angka 3,35 ini menandakan bahwa dari 34 mahasiswa tersebut memberikan skor rata-rata dengan kriteria setuju, atau secara keseluruhan, mahasiswa merespons bahwa pada pembelajaran PAI (Pendidikan Agama Islam) menggunakan modul dapat menimbulkan motivasi kepada mahasiswa untuk belajar lebih jauh terkait "Sedekah, Hibah, dan Hadiah". Sedangkan pada perhitungan persentase jawaban mahasiswa per kriteria didapatkan sebesar 83,82352941 \% atau dibulatkan sebesar 83,82\%. Berdasarkan skala Likert, angka ini masuk ke dalam kategori respons sangat tinggi.Hal ini menunjukkan bahwa secara menyeluruh, mahasiswa kelas B1 merespons dengan sangat baik butir pernyataan nomor 3 ini.

Pernyataan nomor 4 yaitu: Dengan adanya modul "Sedekah, Hibah, dan Hadiah", penjelasan dosen lebih mudah dimengerti dan dipahami, dari 34 mahasiswa yang mengisi lembar angket, didapatkan total skor jawaban per kriteria sebesar 113, dengan rata-rata total skor jawaban per kriteria sebesar 3,323529412, atau dibulatkan menjadi 3,32. Angka 3,32 ini menandakan bahwa dari 34 mahasiswa tersebut memberikan skor rata-rata dengan kriteria setuju, atau secara keseluruhan, mahasiswa merespons bahwa pembelajaran PAI (Pendidikan Agama Islam) menggunakan modul dapat membantu mahasiswa untuk lebih mengerti dan memahami penjelasan yang diberikan oleh dosen terkait "Sedekah, Hibah, dan Hadiah". Sedangkan pada perhitungan persentase jawaban mahasiswa per kriteria didapatkan sebesar 83,08823529\% atau dibulatkan sebesar $83,08 \%$. Berdasarkan skala Likert, angka ini masuk ke dalam kategori respons sangat tinggi.Hal ini menunjukkan bahwa butir pernyataan nomor 4 ini secara umum, direspons dengan sangat baik.

Pada butir pernyataan nomor 5 yaitu: Saya tidak merasa kesulitan dalam memahami isi modul Sedekah, Hibah, dan Hadiah, dari 34 mahasiswa yang mengisi lembar angket, didapatkan total skor jawaban per kriteria sebesar 114, dengan rata-rata total skor jawaban per kriteria sebesar 3,352941176, atau dibulatkan menjadi 3,35. Angka 3,35 ini menandakan bahwa dari 34 mahasiswa tersebut mem- 
berikan skor rata-rata dengan kriteria setuju, atau secara keseluruhan, mahasiswa merespons bahwa mahasiswa tidak merasa kesulitan ketika pembelajaran PAI (Pendidikan Agama Islam) dilakukan dengan menggunakan modul "Sedekah, Hibah, dan Hadiah". Sedangkan pada perhitungan persentase jawaban mahasiswa per kriteria didapatkan sebesar 83,82352941 \% atau dibulatkan sebesar 83,82\%. Berdasarkan skala Likert, angka ini masuk ke dalam kategori respons sangat tinggi.Hal ini menunjukkan bahwa secara menyeluruh, mahasiswa kelas B1 merespons dengan sangat baik butir pernyataan nomor 5 ini.

Selanjutnya pada butir pernyataan nomor 6 yaitu: Struktur kalimat yang digunakan dalam modul ini jelas dan sederhana, dari 34 mahasiswa yang mengisi lembar angket, didapatkan total skor jawaban per kriteria sebesar 112, dengan rata-rata total skor jawaban per kriteria sebesar 3,294117647, atau dibulatkan menjadi 3,29. Angka 3,29 ini menandakan bahwa dari 34 mahasiswa tersebut memberikan skor rata-rata dengan kriteria setuju, atau secara keseluruhan, mahasiswa merespons bahwa dalam modul "Sedekah, Hibah, dan Hadiah ini menggunakan struktur kalimat yang jelas dan sederhana. Sedangkan pada perhitungan persentase jawaban mahasiswa per kriteria didapatkan sebesar 82,35294118\% atau dibulatkan sebesar 83,35\%. Berdasarkan skala Likert, angka ini masuk ke dalam kategori respons sangat tinggi.Secara umum, hal ini menunjukkan bahwa butir pernyataan no 6 ini direpon dengan sangat baik oleh mahasiswa kelas B1.

Pada butir pernyataan nomor 7 yaitu: Bahasa yang digunakan dalam modul ini mudah dipahami dan komunikatif, dari 34 mahasiswa yang mengisi lembar angket, didapatkan total skor jawaban per kriteria sebesar 115, dengan rata-rata total skor jawaban per kriteria sebesar 3,382352941, atau dibulatkan menjadi 3,38. Angka 3,38 ini menandakan bahwa dari 34 mahasiswa tersebut memberikan skor rata-rata dengan kriteria setuju, atau secara keseluruhan, mahasiswa merespons bahwa bahasa yang digunakan dalam modul "Sedekah, Hibah, dan Hadiah" ini mudah dipahami dan komunikatif. Sedangkan pada perhitungan persentase jawaban mahasiswa per kriteria didapatkan sebesar 84,55882353 $\%$ atau dibulatkan sebesar 84,56 \%. Berdasarkan skala Likert, angka ini masuk ke dalam kategori respons sangat tinggi.Hal ini menunjukkan bahwa secara menyeluruh, mahasiswa kelas B1 merespons dengan sangat baik butir pernyataan nomor 7 ini.

Pernyataan nomor 8 yaitu: Penyajian modul disesuaikan dengan daftar pustaka, dari 34 mahasiswa yang mengisi lembar angket, didapatkan total skor jawaban per kriteria sebesar 116, dengan rata-rata total skor jawaban per kriteria sebesar 3,411764706, atau dibulatkan menjadi 3,41. Angka 3,41 ini menandakan bahwa dari 34 mahasiswa tersebut memberikan skor rata-rata dengan kriteria setuju, atau secara keseluruhan, mahasiswa merespons bahwa pada modul "Sedekah, Hibah, dan Hadiah" ini disajikan daftar pustaka yang sesuai dengan isi modul tersebut. Sedangkan pada perhitungan persentase jawaban mahasiswa per kriteria didapatkan sebesar 85,29411765 \% atau dibulatkan sebesar 83,29 \%. Berdasarkan skala Likert, angka ini masuk ke dalam kategori respons sangat tinggi. Secara umum hal ini menunjukkan bahwa butir pernyataan nomor 8 ini direspons dengan sangat baik oleh mahasiswa kelas B1.

Selanjutnya pada butir pernyataan nomor 9 yaitu: Dengan adanya modul "Sedekah, Hibah, dan Hadiah", saya dapat belajar secara mandiri, dari 34 mahasiswa yang mengisi lembar angket, didapatkan total skor jawaban per kriteria sebesar 113, dengan rata-rata total skor jawaban per kriteria sebesar 3,323529412, atau dibulatkan menjadi 3,32. Angka 3,32 ini menandakan bahwa dari 34 mahasiswa tersebut memberikan skor rata-rata dengan kriteria setuju, atau secara keseluruhan, mahasiswa merespons bahwa modul "Sedekah, Hibah, dan Hadiah", dapat membuat mahasiswa belajar secara mandiri pada mata kuliah PAI (Pendidikan Agama Islam). Sedangkan pada perhitungan persentase jawaban mahasiswa per kriteria didapatkan sebesar 83,08823529\% atau dibulatkan sebesar 83,09\%. Berdasarkan skala Likert, angka ini masuk ke dalam kategori respons sangat tinggi.Hal ini menunjukkan bahwa secara menyeluruh, mahasiswa kelas B1 merespons dengan sangat baik butir pernyataan nomor 9 ini.

Terakhir, yaitu pada butir pernyataan nomor 10: Modul dilengkapi dengan gambar, tabel dan grafik yang menarik, dari 34 mahasiswa yang mengisi lembar angket, didapatkan total skor jawaban per kriteria sebesar 101, dengan rata-rata total skor jawaban per kriteria sebesar 2,970588235, atau dibulatkan menjadi 2,97. Angka 2,97 ini menandakan bahwa 
dari 34 mahasiswa tersebut memberikan skor ratarata dengan kriteria tidak setuju, atau secara keseluruhan, mahasiswa merespons bahwa modul tidak dilengkapi dengan gambar, tabel dan grafik. Hal ini disebabkan tidak adanya grafik yang dimunculkan didalam modul tersebut. Sedangkan pada perhitungan persentase jawaban mahasiswa per kriteria didapatkan sebesar 74,26470588 \% atau dibulatkan sebesar 74,26 \%. Berdasarkan skala Likert, angka ini masuk ke dalam kategori respons tinggi. Secara umum, hal ini menunjukkan bahwa butir pernyataan nomor 10 ini direspons dengan baik oleh mahasiswa kelas B1.

Lebih lanjut, interpretasi rata-rata skor angket yang menunjukkan responsmasing-masing mahasiswa terhadap tiap butir pernyataan dalam angket disajikan pada Tabel 2.

Tabel 2. Interpretasi rata-rata skor angket dengan menggunakan skala Likert

\begin{tabular}{|c|c|c|c|}
\hline No & $\begin{array}{c}\text { Kode } \\
\text { mahasiswa }\end{array}$ & $\begin{array}{l}\text { Persentase rata-rata } \\
\text { skor tiap mahasiswa }\end{array}$ & Kategori respons mahasiswa \\
\hline 1 & APR & $82.5 \%$ & Sangat Tinggi \\
\hline 2 & AML & $90 \%$ & Sangat Tinggi \\
\hline 3 & AWL & $87.5 \%$ & Sangat Tinggi \\
\hline 4 & DPE & $87.5 \%$ & Sangat Tinggi \\
\hline 5 & DM & $85 \%$ & Sangat Tinggi \\
\hline 6 & DFR & $85 \%$ & Sangat Tinggi \\
\hline 7 & DG & $77.5 \%$ & Tinggi \\
\hline 8 & ETSC & $87.5 \%$ & Sangat Tinggi \\
\hline 9 & EJEP & $80 \%$ & Tinggi \\
\hline 10 & EN & $77.5 \%$ & Tinggi \\
\hline 11 & FL & $82.5 \%$ & Sangat Tinggi \\
\hline 12 & FWD & $75 \%$ & Tinggi \\
\hline 13 & HM & $85 \%$ & Sangat Tinggi \\
\hline 14 & IESS & 0 & - \\
\hline 15 & $\mathrm{KY}$ & $82.5 \%$ & Sangat Tinggi \\
\hline 16 & LZL & $82.5 \%$ & Sangat Tinggi \\
\hline 17 & MFA & $90 \%$ & Sangat Tinggi \\
\hline 18 & MS & $80 \%$ & Tinggi \\
\hline 19 & MA & $82.5 \%$ & Sangat Tinggi \\
\hline 20 & $\mathrm{NE}$ & $82.5 \%$ & Sangat Tinggi \\
\hline 21 & $\mathrm{OA}$ & $87.5 \%$ & Sangat Tinggi \\
\hline 22 & PG & $82.5 \%$ & Sangat Tinggi \\
\hline 23 & RM & $75 \%$ & Tinggi \\
\hline 24 & RY & $85 \%$ & Sangat Tinggi \\
\hline 25 & RDP & $85 \%$ & Sangat Tinggi \\
\hline 26 & RT & $80 \%$ & Tinggi \\
\hline 27 & SAH & $82.5 \%$ & Sangat Tinggi \\
\hline 28 & SG & $87.5 \%$ & Sangat Tinggi \\
\hline 29 & SR & $82.5 \%$ & Sangat Tinggi \\
\hline 30 & TM & $80 \%$ & Tinggi \\
\hline 31 & TS & $82.5 \%$ & Sangat Tinggi \\
\hline 32 & YAL & $80 \%$ & Tinggi \\
\hline 33 & BRS & $80 \%$ & Tinggi \\
\hline 34 & $\mathrm{~F}$ & $85 \%$ & Sangat Tinggi \\
\hline 35 & $\mathrm{M}$ & $80 \%$ & Tinggi \\
\hline \multicolumn{2}{|c|}{$\begin{array}{c}\text { Rata-rata Persentase } \\
\text { jawaban mahasiswa per } \\
\text { kriteria }\end{array}$} & $82,86764706 \%$ & Sangat tinggi \\
\hline
\end{tabular}

Hasil penelitian yang diperoleh melalui angket menunjukkan bahwa terdapat 11 orang mahasiswa memberikan respons dengan kriteria "tinggi" dan terdapat 23 orang mahasiswa memberikan respons dengan kriteria "sangat tinggi" terhadap 10 butir pernyataan angket tersebut.
Respons dengan kriteria "tinggi” yang diberikan antara lain: DG dengan skor $77.5 \%$, EJEP dengan skor $80 \%$, EN dengan skor $77.5 \%$, FWD dengan skor $75 \%$, MS dengan skor $80 \%$, RM dengan skor $75 \%$, RT dengan skor $80 \%$, TM dengan skor $80 \%$, YAL dengan skor $80 \%$, BRS dengan skor $80 \%$, dan M dengan skor $80 \%$. Hal ini menunjukkan bahwa terdapat $32.35 \%$ mahasiswa memberikan respons dengan kriteria "tinggi".

Sementara itu, respons dengan kriteria "sangat tinggi" yang diberikan antara lain: APR dengan skor $82.5 \%$, AML dengan skor $90 \%$, AWL dengan skor $87.5 \%$, DPE dengan skor $87.5 \%$, DM dengan skor $85 \%$, DFR dengan skor $85 \%$, ETSC dengan skor 87.5 $\%$, FL dengan skor $82.5 \%$, HM dengan skor $85 \%$, KY dengan skor $82.5 \%$, LZL dengan skor $82.5 \%$, MFA dengan skor $90 \%$, MA dengan skor $82.5 \%$, NE dengan skor $82.5 \%$, OA dengan skor $87.5 \%$, PG dengan skor $82.5 \%$, RY dengan skor $85 \%$, RDP dengan skor $85 \%$, SAH dengan skor $82.5 \%$, SG dengan skor $87.5 \%$, SR dengan skor $82.5 \%$, TS dengan skor 82.5 $\%$, serta $\mathrm{F}$ dengan skor $85 \%$. Hal ini menunjukkan bahwa terdapat $67,65 \%$ mahasiswa memberikan respons dengan kriteria "sangat tinggi".

Berdasarkan Tabel 2 dapat diketahui secara umum mahasiswa memberi respons positif terhadap pembelajaran mata kuliah Pendidikan Agama Islam dengan menggunakan modul "Sedekah, Hibah, dan Hadiah". Sebagaimana yang dinyatakan Riyana dan Susilana (2007) bahwa penggunaan media (dalam penelitian ini adalah modul "Sedekah, Hibah, dan Hadiah") dalam proses pembelajaran memiliki beberapa kegunaan, di antaranya memperjelas pesan agar tidak terlalu verbalistis, mengatasi keterbatasan ruang, waktu, tenaga, dan daya indera, dapat menimbulkan gairah belajar, serta memungkinkan anak belajar mandiri. Lebih lanjut dinyatakan bahwa penggunaan media (dalam penelitian ini adalah modul "Sedekah, Hibah, dan Hadiah") dalam pembelajaran memiliki beberapa kontribusi, antara lain agar penyampaian pesan pembelajaran dapat lebih terstandar, pembelajaran menjadi lebih menarik, pembelajaran menjadi lebih interaktif, kualitas pembelajaran meningkat, proses pembelajaran dapat berlangsung tak terbatas waktu dan ruang, sikap positif siswa terhadap materi pembelajaran serta proses pembelajaran meningkat, serta peran guru berubah ke arah yang positif. 
33 NUANSA Vol. XI, No. 1, Juni 2018

\section{Kesimpulan}

Respons mahasiswa Semester 3 kelas B1 Tahun Ajaran 2016-2017 di Akademi Farmasi Al-Fatah ditunjukkan melalui perhitungan hasil angket respons yang berisi 10 butir pernyataan. Perhitungan terhadap hasil angket menunjukkan bahwa terdapat 11 orang mahasiswa memberikan respons dengan kriteria "tinggi" dan terdapat 23 orang mahasiswa memberikan respons dengan kriteria "sangat tinggi" terhadap 10 butir pernyataan angket tersebut. Persentase rata-rata skor semua mahasiswa yaitu sebesar 82,86764706 \% dan tergolong ke dalam kriteria sangat tinggi. Dapat disimpulkan bahwa mahasiswa Semester 3 kelas B1 Tahun Ajaran 20162017 di Akademi Farmasi Al-Fatah memberikan respons yang positif terhadap pembelajaran mata kuliah Pendidikan Agama Islam menggunakan modul "Sedekah, Hibah, dan Hadiah".

\section{Daftar Pustaka}

Anwar, Ilham,Pengembangan Bahan Ajar.(Bahan Kuliah Online. Direktori Upi. Bandung, 2010) Abdul Aziz Muhammad Azam, Fiqh Muamalah (Jakarta : Amzah), h.435-451

Ahmad Wardi Muslic, Fiqh Muamalah (Jakarta: Amzah, 2010)

Didin Hafidhudin, Zakat dalam Perekonomian Modern ( Jakarta: Gema Insani,2002)
Na n ik | Respons Mahasiswa Terhadap Penggunaan Modul

Dimyati Dan Mudjiono, Belajar Dan Pembelajaran (Jakarta: Rineka Cipta,2009).

Direktorat Jenderal Manajemen Pendidikan Dasar Dan MenengahTeknik Penyusunan Modul (Jakarta: Departemen Pendidikan Nasional,2008)

Helmi Karim, Fiqh Muamalah, (Jakarta : Raja Grafindo Persada,2002)

Muhammad Sayyid Sabiq, Fiqih Sunnah Jilid 5 (Jakarta: Pena Pundi Aksara), h. 495-509,551,

Riduwan. Metode Dan Teknik Menyusun Proposal Penelitian.( Bandung: Alfabeta,2009)

Riyana, Cepi \& Rudi Susilana.Media Pembelajaran (Bandung: CV. Wacana Prima, 2007)H. 1-10

Sudijono, A. 2010.Pengantar Statistik Pendidikan. Jakarta: Pt Raja Grafindo Persada.

Sudjana, Nana dan Ahmad Rivai. 2007. Media Pengajaran. Bandung: Sinar Baru Algesindo. Hlm. $1-7$

Suparman, Atwi. 1997. Desain Instruktional. Jakarta: Rineka Cipta

Supiana, M.Karman, 2003. Materi Pendidikan Agama Islam, Bandung: Remaja Rosda Karya

Utomo, Tjipto. 1991. Peningkatan Dan Pengembangan Pendidikan. (Jakarta: Gramedia Pustaka Utama,1991) 
雄

34 NUANSA Vol. XI, No. 1, Juni 2018
高

Na n ik | Respons Mahasiswa Terhadap Penggunaan Modul 34 